\title{
Working
}

\section{Incomplete Markets and Trade}

\section{Paul Willen}

\begin{abstract}
:
In this paper, we show that incomplete markets lead to trade imbalances. We use a two-period general equilibrium model with countries composed of heterogeneous households. We look at a world where, when markets are complete, countries engage in balanced trade; and we show that when some of those markets are absent, trade imbalances emerge. Market incompleteness across countries causes trade imbalances because national income in some countries is more sensitive to risky asset payoffs than in others. Market incompleteness within countries causes trade imbalances because superior risk-sharing in one country leads to a lower precautionary demand for saving.
\end{abstract}

JEL Codes: D52, F30

Paul Willen is a Senior Economist at the Federal Reserve Bank of Boston. His email address is paul.willen@bos.frb.org.

This paper, which may be revised, is available on the web site of the Federal Reserve Bank of Boston at http://www.bos.frb.org/economic/wp/index.htm.

The views expressed in this paper are solely those of the author and do not reflect official positions of the Federal Reserve Bank of Boston or the Federal Reserve System.

This paper encompasses and supersedes my earlier paper "The effect of financial sophistication on the trade balance." Helpful comments and suggestions from Bill Brainard, Doug Irwin, Borja Larrain, and Ken Rogoff are greatly appreciated. John Geanakoplos invested a lot of time and energy in this project, for which I am grateful. Thanks to students in the graduate international finance class at Princeton in the Spring of 2000 for patiently sitting through a draft of this paper.

This version: December 2004 


\section{Introduction}

In this paper, we explore the effects of financial markets on international trade. Researchers have recently documented significant differences in the structure and function of financial markets across countries. ${ }^{1}$ Much of this research explores how such differences can affect the level and growth of economic activity, but little touches on the question we address, namely, how financial markets affect the balance of trade in goods across countries. $^{2}$

Our main results show that incomplete markets lead to trade imbalances. We look at a world where, when markets are complete, countries engage in balanced trade; and we show that when some of those markets are absent, trade imbalances emerge. We explore and distinguish between markets that are incomplete across countries, that is, where risky assets do not span national income, and markets that are incomplete within a country, that is, where assets do not span all individual household income streams.

When markets are incomplete across countries, we show that, for a small open economy, the more highly correlated national income with internationally traded risky assets, the lower the trade deficit. The intuition is straightforward. The more highly correlated national income is with risky assets, the more a country can hedge nationalincome risk. But reduced risk also means reduced return, so households reduce consumption, which reduces the trade deficit.

Even if markets are complete across countries, market incompleteness within countries can still lead to trade imbalances. The logic is that more-complete markets lead to better risk-sharing across individual households; better risk-sharing results in lower demand for precautionary saving; lower demand for precautionary saving leads to higher consumption in period zero and thus to a higher trade deficit in period zero and a smaller deficit (or larger surplus) in period one.

In the paper, we also make some contributions to the theory of incomplete markets and to the theory of international trade in financial assets. First, in Section 3, we extend Svensson's (1988) laws of comparative advantage for international trade in assets to economies with heterogeneous agents. Second, in Section 4, we show that the $R^{2}$ of a regression provides a useful measure of market incompleteness both for countries and for individuals.

The remainder of the introduction consists of a discussion of the real-world rele-

\footnotetext{
${ }^{1}$ See Levine (2004) for a survey of the literature on financial markets and growth, which argues that significant differences exist in both the level of financial market activity and its character, that is, whether it is market or bank-based.

${ }^{2}$ Boyd and Smith (1992) and Gertler and Rogoff (1990) are exceptions to this.
} 
vance of our theory and a brief literature review. Then, Section 2 outlines the model. Section 3 defines and proves laws of comparative advantage for risky and riskless assets. Section 4 characterizes the trade deficit. Section 5 provides some concluding thoughts.

\section{$1.1 \quad$ Literature review}

This paper draws on both the literature on international finance and the literature on incomplete markets.

This paper builds on work on international trade in financial assets. Svensson (1988) and Obstfeld and Rogoff (1996) prove laws of comparative advantage for trade in assets for representative agent economies. In Section 3, we extend these results to heterogeneous agent economies with incomplete markets. Errunza and Losq $(1985$; 1989) use a model with exponential utility and normal returns to explore questions about market segmentation. Their model differs from ours in that households consume only in period one, and all income risks are spanned by risky assets. Adler and Dumas (1983) provides a classic survey of issues in portfolio choice and asset pricing in an international context. Many other authors have used market incompleteness to explain the joint dynamics of consumption and income (Baxter and Crucini, 1995), but the focus of this paper is the level, rather than the dynamics of consumption and income.

The results in this paper also extend work in the incomplete markets literature. (See Geanakoplos (1990) for an introduction.) Demange and Laroque (1995) lay out the basic model used in the paper and prove some fundamental results about risk-sharing. Willen (forthcoming) looks at the effects of new financial markets on consumption and welfare. Allowing trade in a risky asset amounts to opening a new market for the country or countries in question, so some of the results in this paper bear a resemblance to results in that paper. Elul (1997) proved that addition of a new financial market always reduces the price of the riskless asset in an incompletemarkets exponential-normal model, a result that plays a key role in Section 4.2.

Gertler and Rogoff (1990) prove a related result. They consider a rich and a poor country, each with firms that face moral hazard problems in borrowing. They show that if rich-country borrowers can self-finance more easily than poor-country borrowers, then the moral hazard problem is smaller in the rich country and capital will flow from the poor country to the rich country, creating trade imbalances. 


\section{Basic model}

The model is a standard two-period exponential-normal general equilibrium with incomplete markets model. (See Demange and Laroque (1995) and Willen (forthcoming) for more on these models.) The assumptions of exponential utility (Condition 1), and normally distributed endowments and asset payoffs (Condition 2), common in the literature, enable us to solve the model analytically but also lead to well-known shortcomings. In our case, the main shortcoming is that exponential utility implies that absolute tolerance for risk is unaffected by the level or variance of consumption, meaning that when a country goes from autarky to international trade, its appetite for risk stays the same despite the fact that both the level and the variance of consumption change.

\subsection{Description of the economy}

There is one consumption good; two time periods, $t=0,1 ; H$ households in the world, $h=1, \ldots, H$; and $G$ countries, $g=1, \ldots, G$, where a country is a collection of households, $h \in g \cdot{ }^{3}$ A consumption path is a random vector $C^{h}=\left(\tilde{c}_{t}^{h}\right)_{t \in\{0,1\}}$. All agents have time-additive, separable, von Neumann-Morgenstern utility functions, and our first important condition is that the period utility function is exponential. ${ }^{4}$

Condition 1 All agents have exponential utility.

$$
U^{h}\left(C^{h}\right)=\mathrm{E}_{0}\left[\sum_{t=0}^{1}\left(\delta_{h}\right)^{t} \frac{-1}{A^{h}} \exp \left(-A^{h} c_{t}^{h}\right)\right],
$$

where $A^{h}$ is the coefficient of absolute risk aversion and $\delta_{h}$ is the subjective rate of time preference.

Let $A^{g}=\left(1 / H^{g}\right) \sum_{h \in g}\left(1 / A^{h}\right)$ be the harmonic mean of household absolute risk aversion in country $g, A$ be the harmonic mean of absolute risk aversion for the world, and $\delta^{g}=\Pi_{h \in g} \delta_{h}^{\left(A^{g} / A^{h} H_{g}\right)}$. Variables with a " $g$ " or " $h$ " superscript refer to country- and household- level quantities, respectively, and similar variables without any superscript refer to global quantities. Household endowments, are $\left(y_{t}^{h}\right)_{t=0,1}, \mathbf{Y}_{t}$

\footnotetext{
${ }^{3}$ Each person is a member of a country. A country could be composed of a single household.

${ }^{4}$ The basic asset pricing and portfolio selection results do not depend on the exponential formulation. If one replaces $A^{h}$ in the formulas with $\frac{-\mathrm{E}\left(u^{h \prime \prime}\left(\tilde{c}_{1}^{h}\right)\right)}{\mathrm{E}\left(u^{h \prime}\left(\tilde{c}_{1}^{h}\right)\right)}$, the coefficient of global absolute risk aversion, one can still get simple formulas. However, the consumption formulas and the behavior of the economy with innovations are no longer so simple.
} 
is the $H$ dimensional vector of period- $t$ endowment, and per capita country-level endowment is $\tilde{y}_{t}^{g}$.

There are $J+1$ assets: (1) $J$ risky assets, which pay off $\underset{J \times 1}{\tilde{x}}$, and (2) a riskless asset, which always pays off one dollar with certainty, $x_{0}=1$. Let $\tilde{\mathbf{x}}$ be the $J$ dimensional vector of risky asset payoffs.

Let the vector of endowments and asset payoffs be $\mathbf{\Phi}=\left(\begin{array}{lllllll}\widetilde{y}_{1}^{1} & \ldots & \widetilde{y}_{1}^{H} & \widetilde{x}_{1} & \ldots & \widetilde{x}_{J}\end{array}\right)$.

Condition 2 Asset payoffs and endowments are distributed jointly normally:

$$
\boldsymbol{\Phi} \sim N(\mathrm{E}(\boldsymbol{\Phi}), \mathbf{S})
$$

where $S=\left[\begin{array}{c|c}\boldsymbol{\Xi} & \boldsymbol{\beta} \\ \hline \boldsymbol{\beta}^{\prime} & \boldsymbol{\Sigma} .\end{array}\right]$

The covariance of asset returns and income shocks $\beta$ is a key ingredient in the analysis that follows. Let $\boldsymbol{\beta}^{h}, \boldsymbol{\beta}^{g}$ and $\overline{\boldsymbol{\beta}}$ be the $J$-dimensional vectors of covariances of household income for household $h$, average household income for residents of country $g$, and average household income for the entire world, respectively.

We allow individuals to trade some country-specific subset $J^{g}$ of the risky assets, meaning that they choose a $J^{g}$-dimensional portfolio of risky assets $\boldsymbol{\omega}^{h}$ and invest $\omega_{0}^{h}$ in the riskless asset. We assume that individuals have no endowments of securities and that there are no limits on $\boldsymbol{\omega}$ - unlimited short sales are possible. ${ }^{5}$ Consider a perfectly competitive economy in which consumption goods prices are normalized to be one, the price of the riskless asset is denoted by $\pi_{0}$, and risky asset prices are denoted by $\pi \in \mathbb{R}^{J}$.

Country-level security holdings are $\omega_{0}^{g}=\sum_{h \in g} \omega_{0}^{h}$ and $\boldsymbol{\omega}^{g}=\sum_{h \in g} \boldsymbol{\omega}^{h}$. Note that these are not averages but total holdings.

The budget set is:

$$
B^{h}\left(\pi_{0}, \boldsymbol{\pi}\right)=\left\{\begin{array}{cc} 
& c_{0}+\sum_{j=0}^{J} \omega_{j}^{h} \pi_{j}=y_{0} \\
\left(c_{t}^{h}, \omega_{t}^{h}\right)_{t \in\{0,1\}} \ni & c_{1}=y_{1}+\sum_{j=0}^{J} \omega_{j}^{h} \widetilde{x}_{j} \\
& \omega_{j}^{h}=0 \text { if } j \notin J^{g}
\end{array}\right\} .
$$

Unless otherwise noted, we assume that all households can trade all assets. An equilibrium $\left(\boldsymbol{\pi},\left(C^{h}, \boldsymbol{\omega}^{h}\right)_{h \in H}\right)$ is a price vector and a consumption profile such that: (1) Each household optimally chooses within her budget set and (2) Markets clear: for all $t: \sum_{h \in H} \tilde{c}_{t}^{h}=\sum_{h \in H} \tilde{y}_{t}^{h}$ and $\sum_{h \in H} \boldsymbol{\omega}^{h}=0$.

\footnotetext{
${ }^{5}$ Obviously, if an asset is not included in set $J^{g}$, then individuals in country $g$ cannot trade the asset at all; however if $j \in J^{g}$, then there are no restrictions at all.
} 


\section{Trade in assets}

In this section, we calculate a country's trade balance for assets, showing that we can analyze international trade in assets using standard comparative-advantage arguments. Specifically, Proposition 1 shows that if the autarky price for country $g$ of a risky asset $j$ exceeds the world price, then country $g$ imports risky asset $j$; and the more the autarky excess return exceeds the world price, the more country $g$ imports risky asset $j$. Proposition 2 shows that all else being equal, the higher the autarky price of the riskless asset, the more a country imports the riskless asset - that is, the more a country saves.

Before we go on, we introduce one more piece of notation. It will often be convenient to measure the price of an asset as the excess payoff over the riskless asset, which, in an abuse of terminology, we will call the excess return. So, we will often use the $J$-dimensional excess returns vector $\mathbf{P}$ whose representative element is $\mathrm{E}\left(\tilde{x}_{j}\right)-\frac{\pi_{j}}{\pi_{0}}$

- the difference between the return on an investment of $\pi_{j}$ in asset $j\left(\mathrm{E}\left(\tilde{x}_{j}\right)\right)$ and the return on an investment of $\pi_{j}$ in the riskless asset $\left(\frac{\pi_{j}}{\pi_{0}}\right)$.

We follow the custom in the international trade literature, as in, for example, Dixit and Norman (1980), and we characterize country-level demand for assets in terms of global and autarky prices, where the autarky price is the price that would prevail in the absence of any international trade. We denote the autarky prices for the risky and riskless assets $\pi_{0}^{g}$ and $\boldsymbol{\pi}^{g}$, respectively, and the autarky excess return vector, $\mathbf{P}^{g}$. We also follow the international trade literature in referring to our formulations of national demand for assets as "laws of comparative advantage," drawing on the intuition that if a country has comparative advantage in a particular asset, then a relatively low price for that asset will prevail in autarky, and that country will export the asset.

Proposition 1 (Law of comparative advantage for risky assets) Household demand for risky assets is as follows:

$$
\boldsymbol{\omega}^{h}=\boldsymbol{\Sigma}^{-1}\left[\frac{\mathrm{E}(\tilde{\mathbf{x}})-\frac{\boldsymbol{\pi}}{\pi_{0}}}{A^{h}}-\boldsymbol{\beta}^{h}\right]=\boldsymbol{\Sigma}^{-1}\left[\mathbf{P} / A^{h}-\boldsymbol{\beta}^{h}\right] .
$$

Risky asset demand for country $g$ is as follows:

$$
\boldsymbol{\omega}^{g}=\frac{H^{g}}{\pi_{0} A^{g}} \boldsymbol{\Sigma}^{-1}\left(\boldsymbol{\pi}^{g}-\boldsymbol{\pi}\right)=\frac{H^{g}}{A^{g}} \boldsymbol{\Sigma}^{-1}\left(\mathbf{P}-\mathbf{P}^{g}\right) .
$$

The autarky equilibrium price is $\boldsymbol{\pi}^{g}=\pi_{0}\left[\mathrm{E}(\tilde{\mathbf{x}})-A^{g} \boldsymbol{\beta}^{g}\right]$, and $\mathbf{P}^{g}=A^{g} \boldsymbol{\beta}^{g}$. The global equilibrium price is $\boldsymbol{\pi}=\pi_{0}[\mathrm{E}(\tilde{\mathbf{x}})-A \overline{\boldsymbol{\beta}}]$, and $\mathbf{P}=A \overline{\boldsymbol{\beta}}$. 
Proof: The first-order conditions for the household optimization problem are:

$$
\begin{aligned}
& \pi_{0} u_{C}^{h}\left(c_{0}^{h}\right)=\delta^{h} \mathrm{E}\left(u_{C}^{h}\left(\widetilde{c}_{1}^{h}\right)\right), \\
& \pi_{j} u_{C}^{h}\left(c_{0}^{h}\right)=\delta^{h} \mathrm{E} u_{C}^{h}\left(\widetilde{c}_{1}^{h}\right) \mathrm{E}\left(\tilde{x}_{j}\right)+\delta^{h} \mathrm{E} u_{C C}^{h}\left(\widetilde{c}_{1}^{h}\right) \operatorname{cov}\left(\widetilde{c}_{1}^{h}, \tilde{x}_{j}\right),
\end{aligned}
$$

where equation (4) comes from the definition of covariance and Stein's lemma. Divide equation (4) by equation (3) and note that $-\frac{\mathrm{E} u_{C C}^{h}\left(\tilde{c}_{1}^{h}\right)}{\mathrm{E} u_{C}^{h}\left(\widehat{c}_{1}^{h}\right)}=A^{h}$ to get:

$$
\left(1 / A^{h}\right)\left[\mathrm{E}\left(\tilde{x}_{j}\right)-\frac{\pi_{j}}{\pi_{0}}\right]=\operatorname{cov}\left(\widetilde{c}_{1}^{h}, \tilde{x}_{j}\right) \quad j=1, \ldots, J
$$

Substituting in the period-one budget constraint yields equation (1). To solve for prices, average equation (5) across all traders, and use the fact that in autarky, $\tilde{c}_{1}^{g}=\tilde{y}_{1}^{g}$ and that in global equilibrium, $\tilde{c}_{1}=\tilde{y}_{1}$. To get equation (2), average equation (1) across $h \in g$, and use the fact that $\boldsymbol{\beta}^{g}=\mathbf{P}^{g} / A^{g}$.

What generates a high or low autarky price of asset $j$ and thus makes a country import or export risk? Assume there is a single risky asset. Proposition 1 leads us to focus on the level of $\beta_{j}^{g}$ and on risk aversion. Specifically, a higher $\beta_{j}^{g}-$ a high covariance of average income with the risky asset - means that a country already has considerable exposure to that asset, and high supply of risk leads to a low price or a high excess payoff, making the asset attractive to foreigners and leading to exports. Higher risk aversion implies higher disutility of risk at any level of exposure and thus leads to a lower autarky price and a high excess payoff, for any risky asset.

What happens with more than one asset? If the additional asset is orthogonal to all the other assets, then it is easy to see that the single-asset law of comparative advantage will hold. If all assets are orthogonal (if $\boldsymbol{\Sigma}$ is diagonal), then the law of comparative advantage holds in the strong sense. In general, comparative advantage holds in a weaker sense. Specifically, equation (2) implies that: ${ }^{6}$

$$
\boldsymbol{\omega}^{g} \cdot\left(\boldsymbol{\pi}^{g}-\boldsymbol{\pi}\right) \geq 0
$$

Equation (6) does not imply that the law of comparative advantage holds asset-byasset or even that there is a correlation between the excess return differentials and holdings. However, in the literature, this is typically interpreted as a "tendency" (See Svensson 1988), so we interpret equation (6) to say countries with high autarky prices of a given risky asset tend to import that asset.

Now, we consider the balance of trade in the riskless asset.

\footnotetext{
${ }^{6}$ Solve for $\left(\mathbf{P}-\mathbf{P}^{g}\right)$. Then equation (2) implies that $\boldsymbol{\omega}^{g} \cdot\left(\mathbf{P}-\mathbf{P}^{g}\right)=\frac{A^{g}}{H^{g}} \boldsymbol{\omega}^{g /} \boldsymbol{\Sigma} \boldsymbol{\omega}^{g}$. Since $\boldsymbol{\Sigma}$ is positive semi-definite, this must be positive.
} 
Proposition 2 (Law of comparative advantage for the riskless asset) Riskless asset demand for country $g$ is as follows:

$$
\omega_{0}^{g}=\frac{H^{g}}{1+\pi_{0}}(\frac{1}{A_{g}^{*}} \ln \frac{\pi_{0}^{g}}{\pi_{0}}-\underbrace{(\mathrm{E}(\tilde{\mathbf{x}})+\boldsymbol{\pi}) \frac{\boldsymbol{\omega}^{g}}{H^{g}}}_{\begin{array}{c}
\text { (1) Effect of risky } \\
\text { assets on mean }
\end{array}}+\underbrace{\frac{1}{H^{g}} \sum_{h \in g} \frac{A^{h}}{2}\left(\operatorname{var}\left(\tilde{c}_{1}^{h}\right)-\operatorname{var}\left(\tilde{c}_{1, g}^{h}\right)\right)}_{\begin{array}{c}
\text { (2) Effect of risky } \\
\text { assets on variance }
\end{array}})
$$

and

$$
\pi_{0}^{g}=\underbrace{\delta^{g}}_{(1)} \exp \underbrace{A^{g}}_{(3)}[\underbrace{y_{0}^{g}-\mathrm{E}\left(\tilde{y}_{1}^{g}\right)}_{(2)}+\underbrace{\frac{1}{H^{g}} \sum_{h \in g} \frac{A^{h}}{2} \operatorname{var}\left(\tilde{c}_{1, g}^{h}\right)}_{(4)}]
$$

Proof: Because $\tilde{x}_{j}$ and $\widetilde{c}_{1}^{h}$ are normal, the first-order condition for the riskless asset (equation (3) is as follows:

$$
\pi_{0} \exp \left(-A^{h} c_{0}^{h}\right)=\delta^{h} \exp \left[-A^{h} \mathrm{E}\left(\widetilde{c}_{1}^{h}\right)+\operatorname{var}\left(A^{h} \widetilde{c}_{1}^{h}\right) / 2\right],
$$

which implies that:

$$
\mathrm{E}\left(\widetilde{c}_{1}^{h}\right)-c_{0}^{h}=\frac{A^{h}}{2} \operatorname{var}\left(\widetilde{c}_{1}^{h}\right)-\frac{1}{A^{h}} \ln \frac{\pi_{0}}{\delta^{h}} .
$$

Summing equation (9) across $h \in g$ and using the household budget constraints and the autarky equilibrium conditions that $y_{0}^{g}=c_{0}^{g}$ and $\tilde{y}_{1}^{g}=\tilde{c}_{1}^{g}$, yields $\pi_{0}^{g}$. Substituting the household budget constraint into equation (9) gives country-level demand:

$$
\left.\omega_{0}^{g}=\frac{H^{g}}{1+\pi_{0}}[\underbrace{y_{0}^{g}-\mathrm{E}\left(\tilde{y}_{1}^{g}\right)+\frac{1}{H^{g}} \sum_{h \in g} \frac{A^{h}}{2} \operatorname{var}\left(\tilde{c}_{1}^{h}\right)+\frac{1}{A^{g}} \ln \delta^{g}}_{=\frac{1}{A^{g}} \ln \pi_{0}^{g}+\frac{1}{H^{g}} \sum_{h \in g} \frac{A^{h}}{2}\left(\operatorname{var}\left(\tilde{c}_{1}^{h}\right)-\operatorname{var}\left(\tilde{c}_{1, g}^{h}\right)\right)}-(\mathrm{E}(\tilde{\mathbf{x}})+\boldsymbol{\pi}) \boldsymbol{\omega}^{h})-\frac{1}{A^{g}} \ln \pi_{0}\right],
$$

which implies equation (7) as shown

What can we say about the trade balance in the riskless asset? Unlike Proposition 1, Proposition 2 does not yield an immediate prediction on the direction of trade. However, using the budget constraint and household portfolio demand from Proposition 1, and the fact that $\boldsymbol{\Sigma}^{-1} \boldsymbol{\beta}^{h} \tilde{\mathbf{x}}=\mathrm{E}\left(\tilde{y}_{1}^{h} \mid \mathbf{x}\right)$, we get

$$
\operatorname{var}\left(\tilde{c}_{1}^{h}\right)=\operatorname{var}\left(\tilde{y}_{1}^{h}-\mathrm{E}\left(\tilde{y}_{1}^{h} \mid \mathbf{x}\right)+1 / A^{h} \boldsymbol{\Sigma}^{-1} \mathbf{P} \tilde{\mathbf{x}}\right) .
$$

Since $\tilde{\mathbf{x}}$ must be orthogonal to $\tilde{y}_{1}^{h}-\mathrm{E}\left(\tilde{y}_{1}^{h} \mid \mathbf{x}\right)$, equation (10) implies that:

$$
\operatorname{var}\left(\tilde{c}_{1}^{h}\right)=\operatorname{var}\left(\tilde{y}_{1}^{h}-\mathrm{E}\left(\tilde{y}_{1}^{h} \mid \mathbf{x}\right)\right)+\left(1 / A^{h}\right)^{2} \mathbf{P}^{\prime} \boldsymbol{\Sigma}^{-1} \mathbf{P} .
$$


Equation (11) implies that:

$$
\frac{1}{H^{g}} \sum_{h \in g} \frac{A^{h}}{2}\left[\operatorname{var}\left(\tilde{c}_{1}^{h}\right)-\operatorname{var}\left(\tilde{c}_{1, g}^{h}\right)\right]=\frac{1}{2}\left(\mathbf{P}^{\prime}+\mathbf{P}^{g \prime}\right) \frac{\boldsymbol{\omega}^{g}}{H^{g}} .
$$

Equation (12) implies that both terms (1) and (2) in equation (7) are proportional to the demand for risky assets. Therefore, we can analyze the demand for the riskless asset conditional on some given level of demand for the risky assets: first, if $\boldsymbol{\omega}^{g}=0$, then a country imports the riskless asset if the autarky price of the riskless asset exceeds the world price; second, conditional on a given $\boldsymbol{\omega}^{g}$, a country will import more of the riskless asset the higher the autarky price.

What determines the autarky price of the riskless asset? Four things: (1) higher expected income growth leads to a lower autarky price; (2) a higher subjective discount factor leads to a higher autarky price; (3) the effect of absolute risk aversion is ambiguous. If the terms inside the brackets sum to a positive (negative) number, higher absolute risk aversion leads to a higher (lower) autarky price. However, absolute risk aversion affects the sign of the sum of the terms, further muddying interpretation; (4) higher sum of household variance of consumption, weighted by absolute risk aversion leads to a higher autarky price. Term (4) plays a central role in our analysis of the trade balance in goods, so we defer discussion to Section 4.

\section{Trade in goods}

Now, we show how incomplete markets affect the balance of trade in goods. Proposition 3 below uses the laws of comparative advantage for risky and riskless assets (Propositions 1 and 2, respectively) to calculate the trade balance and the gains from trade using only absolute risk aversion and the autarky and global asset prices. We analyze Proposition 3 in two steps. First, we consider risky assets that enable countries to share risk with one another. We do this by looking at countries with different autarky excess returns (different $\mathbf{P}^{g}$ ) but the same autarky riskless rates (same $\pi_{0, g}$ ). Second, we examine risky assets that enable households within a country to share risk. We do this by looking at countries with the same autarky excess returns (same $\mathbf{P}^{g}$ ) but different autarky riskless rates (different $\pi_{0, g}$ ).

\section{Proposition 3}

$$
\begin{aligned}
& T D_{0}^{g}=c_{0}^{g}-y_{0}^{g}=\frac{A^{g}}{2\left(1+\pi_{0}\right)} \boldsymbol{\omega}^{\prime} \boldsymbol{\Sigma} \boldsymbol{\omega}+\pi_{0} \frac{H^{g}}{\left(1+\pi_{0}\right) A^{g}} \ln \frac{\pi_{0}}{\pi_{0}^{g}}, \\
& T D_{1}^{g}=\mathrm{E}\left(\tilde{c}_{1}^{g}-\tilde{y}_{1}^{g}\right)=T D_{0}^{g}+\frac{1}{A^{g}}\left(\mathbf{P}^{\prime} \boldsymbol{\Sigma}^{-1} \mathbf{P}-\mathbf{P}^{g \prime} \boldsymbol{\Sigma}^{-1} \mathbf{P}^{g}\right)-\frac{H^{g}}{A^{g}} \ln \frac{\pi_{0}}{\pi_{0}^{g}},
\end{aligned}
$$


and:

$$
G F T^{g}=T D_{0}^{g}+\frac{H^{g}}{A^{g}} \ln \frac{1+\pi_{0}^{g}}{1+\pi_{0}}
$$

where $G F T^{g}=\sum_{h \in g} G F T^{h}$, and $G F T^{h}$ solves

$$
U^{h}\left(c_{0, g}^{h}+G F T^{h}, \tilde{c}_{1, g}^{h}+G F T^{h}\right)=U^{h}\left(c_{0}^{h}, \tilde{c}_{1}^{h}\right) \forall h \in g,
$$

$G F T^{g}$ is always weakly positive and reaches a minimum with respect to $\pi_{0}$ at $\pi_{0}=\pi_{0}^{g}$.

Proof: Equation (12) implies that:

$$
\omega_{0}^{g}=\frac{H^{g}}{1+\pi_{0}} \frac{1}{A^{g}} \ln \frac{\pi_{0}^{g}}{\pi_{0}}-\frac{1}{\pi_{0}} \boldsymbol{\pi} \boldsymbol{\omega}^{g}-\frac{1}{\left(1+\pi_{0}\right) 2 A^{g}} \boldsymbol{\omega}^{\prime} \boldsymbol{\Sigma} \boldsymbol{\omega} .
$$

By the budget constraint and equation (16):

$$
T D_{0}^{g}=c_{0}^{g}-y_{0}^{g}=-\pi_{0} \omega_{0}^{g}-\boldsymbol{\pi}^{g} \boldsymbol{\omega}^{g},
$$

which yields equation (13). The solution for $T D_{1}^{g}$ is somewhat more involved. Under autarky, total consumption equals total income, so equation (9) implies that:

$$
\mathrm{E}\left(\widetilde{y}_{1}^{g}\right)=y_{0}^{g}+\left(1 / H^{g}\right) \sum_{h \in g} \frac{A^{h}}{2} \operatorname{var}\left(\widetilde{c}_{1, g}^{h}\right)-\frac{1}{A^{h}} \ln \frac{\pi_{0}^{g}}{\delta^{h}} .
$$

When a country trades internationally, equation (9) implies that:

$$
\mathrm{E}\left(\widetilde{c}_{1}^{g}\right)=y_{0}^{g}+T D_{0}^{g}+\left(1 / H^{g}\right) \sum_{h \in g} \frac{A^{h}}{2} \operatorname{var}\left(\widetilde{c}_{1}^{h}\right)-\frac{1}{A^{h}} \ln \frac{\pi_{0}}{\delta^{h}} .
$$

Subtracting equation (17) from equation (18) and using equation (12) yields $T D_{1}^{g}$. To calculate the gains from trade, we use equation (3) to show that:

$$
U(C)=\frac{-1}{A^{h}} \exp -A^{h} c_{0}^{h}+\mathrm{E}\left[\frac{-1}{A^{h}} \exp -A^{h} c_{1}^{h}\right]=\frac{-1}{A^{h}}\left(1+\pi_{0}\right) \exp -A^{h} c_{0}^{h} .
$$

Now, we solve: $\frac{-1}{A^{h}}\left(1+\pi_{0}^{g}\right) \exp -A^{h}\left(c_{0, g}^{h}+G F T^{h}\right)=\frac{-1}{A^{h}}\left(1+\pi_{0}\right) \exp -A^{h} c_{0}^{h}$ to get $G F T^{h}=c_{0}^{h}-c_{0, g}^{h}+\frac{1}{A^{h}} \ln \left(\frac{1+\pi_{0}^{g}}{1+\pi_{0}}\right)$ for any individual $h$. Summing across individuals, we get our solution.

\subsection{Markets that enable risk-sharing across countries}

We now focus on countries that differ only with respect to $\mathbf{P}^{g}$, the vector of autarky excess returns on risky assets. Without loss of generality, assume that $\pi_{0}^{g}=\pi_{0}$ for all $g$. We can then re-write equations (13) and (14) as:

$$
\begin{aligned}
T D_{0}^{g} & =\frac{A^{g}}{2\left(1+\pi_{0}\right)} \boldsymbol{\omega}^{g \prime} \boldsymbol{\Sigma} \boldsymbol{\omega}^{g} \\
T D_{1}^{g} & =T D_{0}^{g}+\frac{1}{2}\left(\mathbf{P}^{\prime}+\mathbf{P}^{g \prime}\right) \boldsymbol{\omega}^{g} .
\end{aligned}
$$


We explicate these equations in three steps. First, we show three equivalent interpretations of equation (19), the period-zero trade balance. Second, we use equation (20) to explain what happens to the trade balance in period one. In the first two steps, we take the global price as given, so one can think of this as analysis of a small, open economy. And third, we construct a simple general-equilibrium example, illustrating how incomplete markets induce trade imbalances.

We can interpret the period-zero trade-balance equation (equation (19)) in three equivalent ways. For simplicity, assume there is a single risky asset with unit variance. Then equation (19) and Proposition 1 imply that:

$$
T D_{0}^{g}=\frac{A^{g}}{2\left(1+\pi_{0}\right)}\left(p-p^{g}\right)^{2} .
$$

According to the first-order conditions of the household optimization problem, $p=$ $A^{g} \operatorname{cov}\left(\tilde{c}_{1}^{g}, \tilde{x}\right)$ and, according to Proposition $1, p^{g}=A^{g} \operatorname{cov}\left(\tilde{y}_{1}^{g}, \tilde{x}\right)$. Thus:

$$
T D_{0}^{g}=\frac{A^{g}}{2\left(1+\pi_{0}\right)}\left(\operatorname{cov}\left(\tilde{c}_{1}^{g}, \tilde{x}\right)-\operatorname{cov}\left(\tilde{y}_{1}^{g}, \tilde{x}\right)\right)^{2} .
$$

So, the first interpretation of equation (19) tells us that the trade deficit increases if households change their exposure to asset $\tilde{x}$ when international trade is allowed, regardless of the sign of the change.

To understand why the trade deficit is always positive when $\pi_{0}^{g}=\pi_{0}$, we turn to our second interpretation of equation (19). If we expand the quadratic and use the equilibrium autarky pricing relation in Proposition 1 we get:

$$
T D_{0}^{g}=\frac{A^{g}}{2\left(1+\pi_{0}\right)}\left(\frac{p^{2}}{2 A^{g}}+A^{g}\left(\beta^{g}\right)^{2}-p \beta^{g}\right) .
$$

The first term in equation (21) measures the effect on national wealth of investing in an asset with an excess return different from zero - if the excess return is positive, investors invest positive amounts; if it is negative, they invest negative amounts. Either way, excess returns allow a country to consume more in both periods, leading to a higher trade deficit in period zero. The second term measures the hedging benefit of risky assets. If national income is positively correlated with a particular risky asset, then a country can reduce the variance of consumption, in turn reducing the precautionary saving motive and thus increasing period-zero consumption. Finally, the third term measures the cost of hedging national-income risk. Households in a country can unload national income risk by shorting a risky asset correlated with it. But if the excess return on this asset is positive, such hedging will force a country to consume less in each period. Equation (19) implies that the sum of these three effects must always be positive. 
Finally, we exploit the fact that in international trade equilibrium $p=A \bar{\beta}$ to generate a third interpretation of equation (19). Specifically, since $\bar{\beta}=\operatorname{cov}\left(\tilde{y}_{1}, \tilde{x}\right)$ :

$$
T D_{0}^{g}=\frac{A^{g}}{2\left(1+\pi_{0}\right)} \operatorname{cov}\left(A \tilde{y}_{1}-A^{g} \tilde{y}_{1}^{g}, \tilde{x}\right)^{2}=\operatorname{var}\left(A \hat{y}_{1}-A^{g} \hat{y}_{1}^{g}\right)
$$

where a hat $(\hat{\bullet})$ denotes the expectation of that variable conditional on the set of risky assets, that is,

$$
\hat{y}_{1}^{g}=\mathrm{E}\left(\tilde{y}_{1}^{g} \mid \mathbf{x}\right) .
$$

Thus the trade deficit is proportional the variance of the difference between the projection of national income into the span of traded assets and the projection of world income into the span of traded assets, adjusted for risk aversion. Corollary 1 proves the above result for the multi-asset case.

We now consider the trade deficit in period one. The first-order condition with respect to the riskless asset implies that:

$$
\mathrm{E}\left(\widetilde{c}_{1}^{g}\right)-c_{0}^{g}=\left(1 / H^{g}\right) \sum_{h \in g} \frac{A^{h}}{2} \operatorname{var}\left(\widetilde{c}_{1}^{h}\right)-\frac{1}{A^{g}} \ln \frac{\pi_{0}}{\delta^{g}} .
$$

Autarky equilibrium implies that:

$$
\mathrm{E}\left(\widetilde{y}_{1}^{g}\right)-y_{0}^{g}=\left(1 / H^{g}\right) \sum_{h \in g} \frac{A^{h}}{2} \operatorname{var}\left(\widetilde{c}_{1, g}^{h}\right)-\frac{1}{A^{g}} \ln \frac{\pi_{0}^{g}}{\delta^{g}}
$$

Subtracting equation (24) from equation (23), using $\pi_{0}=\pi_{0}^{g}$ and the definition of the trade deficit yields:

$$
T D_{1}^{g}=T D_{0}^{g}+\frac{1}{H^{g}} \sum_{h \in g} \frac{A^{h}}{2}\left[\operatorname{var}\left(\tilde{c}_{1}^{h}\right)-\operatorname{var}\left(\tilde{c}_{1, g}^{h}\right)\right] .
$$

The trade balance grows over time if the variance of consumption in international trade exceeds the autarky variance of consumption. How does international trade in assets affect the variance of consumption? Equation (12) tells us that:

$$
\frac{1}{H^{g}} \sum_{h \in g} \frac{A^{h}}{2}\left[\operatorname{var}\left(\tilde{c}_{1}^{h}\right)-\operatorname{var}\left(\tilde{c}_{1, g}^{h}\right)\right]=\frac{1}{2}\left(\mathbf{P}^{\prime}+\mathbf{P}^{g \prime}\right) \frac{\boldsymbol{\omega}^{g}}{H^{g}} .
$$

Two equivalent interpretations of equation (25) yield insights. First, equation (25) tells us that if a country uses the risky asset to increase exposure (that is, if $\omega^{g}>0$ ), then the variance of consumption will go up and so will the trade deficit. Similarly, if a country uses the risky asset to reduce exposure (that is, if $\omega^{g}<0$ ), then the variance of consumption will go down and so will the trade deficit. Thus, all else being equal, a 
country that takes a positive position in a risky asset will see an increase in its periodone trade deficit, and a country that takes a negative position will see a reduction in its period-one trade deficit. So, in contrast to period zero, in period one, the sign of holdings in the risky asset affects the direction of trade in goods.

Second, we can again use our equilibrium autarky and international pricing relations to re-write equation (25):

$$
\frac{1}{H^{g}} \sum_{h \in g} \frac{A^{h}}{2}\left[\operatorname{var}\left(\tilde{c}_{1}^{h}\right)-\operatorname{var}\left(\tilde{c}_{1, g}^{h}\right)\right]=\frac{1}{2 A^{h}}\left[\operatorname{var}\left(\hat{y}_{1}\right)-\operatorname{var}\left(\hat{y}_{1}^{g}\right)\right] .
$$

Equation (26) implies that if the variance of the portion of world income spanned by assets exceeds the variance of the portion of national income spanned by assets, the trade deficit goes up. We can use a common statistic from regression analysis to help with our analysis here. For a household income $\tilde{y}_{1}^{h}$, let

$$
R_{h}^{2}=\frac{\operatorname{var}\left(\hat{y}_{1}^{h}\right)}{\operatorname{var}\left(\tilde{y}_{1}^{h}\right)}
$$

$R_{h}^{2}$ measures how much of the variance of income a household can eliminate through risky assets and is analogous to the $R^{2}$ statistic in an OLS regression. $R_{g}^{2}$ and $R^{2}$ are similarly defined for national income and world income, respectively. Suppose $\operatorname{var}\left(\tilde{y}_{1}\right)=\operatorname{var}\left(\tilde{y}_{1}^{g}\right)$; then, we can use $R^{2}$ to re-write equation (26) as:

$$
\frac{1}{H^{g}} \sum_{h \in g} \frac{A^{h}}{2}\left[\operatorname{var}\left(\tilde{c}_{1}^{h}\right)-\operatorname{var}\left(\tilde{c}_{1, g}^{h}\right)\right]=\frac{1}{2 A^{h}} \operatorname{var}\left(\tilde{y}_{1}\right)\left[R^{2}-R_{g}^{2}\right] \text {. }
$$

Higher $R_{g}^{2}$ leads to lower consumption variance and thus to a lower trade deficit in period one.

It is important to note that a country can run a trade deficit in period zero and an expected trade deficit in period one. How can this apparent violation of budget balance take place? Risky assets. Suppose the risky asset pays 10 percent return and the riskless asset pays only five percent. If a country borrows a dollar and invests 95 cents in the risky asset, consumption exceeds income by 5 cents. And, in expectations, the risky asset pays off $0.95 \times 1.15=1.094$ dollars next year, which exceeds debt, which is worth $1.00 \times 1.05=1.05$. Thus consumption, in expectations, exceeds income by 4.4 cents next year as well.

\section{Corollary 1 (Small open economy) Trade deficit in period zero is increasing in}

$$
\operatorname{var}\left(\bar{A} \hat{y}_{1}-A^{g} \hat{y}_{1}^{g}\right)
$$


Proof: By Proposition 1: $\boldsymbol{\omega}^{g \prime} \boldsymbol{\Sigma} \boldsymbol{\omega}^{g}=\operatorname{var}\left(\boldsymbol{\omega}^{\prime} \tilde{\mathbf{x}}\right)=\left(A^{g}\right)^{2} \operatorname{var}\left(\bar{A} \hat{y}_{1}-A^{g} \hat{y}_{1}^{g}\right)$.

We now consider a simple general equilibrium example that illustrates several of the key concepts of this section. Consider two equally sized countries, $a$ and $b$. Assume that $\pi_{0}^{a}=\pi_{0}^{b}, A^{a}=A^{b}$, and that $\operatorname{var}\left(\tilde{y}_{1}^{a}\right)=\operatorname{var}\left(\tilde{y}_{1}^{a}\right)$. Suppose that there is a single risky asset and that $\beta^{a}>\beta^{b}$. What can we say about the trade balance? Suppose there are no risky assets. Then, Proposition 3 implies that $T D_{0}^{a}=T D_{0}^{b}$. In international trade equilibrium, both countries cannot run trade deficits, so neither can and trade is balanced. Since the riskless asset is the only asset traded, no trade deficit in period zero implies balanced trade in period one. Suppose, alternatively, that there are complete markets, in the sense that $\tilde{y}_{1}^{g}=\hat{y}_{1}^{g}$ for both countries. By Proposition 3 and equation (22)

$$
T D_{0}^{a}=T D_{0}^{b}=\frac{A^{g}}{2\left(1+\pi_{0}\right)} \operatorname{var}\left(\tilde{y}_{1}^{a}-\tilde{y}_{1}^{b}\right)+\pi_{0} \frac{H^{g}}{\left(1+\pi_{0}\right) A^{a}} \ln \frac{\pi_{0}}{\pi_{0}^{a}} .
$$

Thus, trade must be balanced in period zero. And $\operatorname{var}\left(\tilde{y}_{1}^{a}\right)=\operatorname{var}\left(\tilde{y}_{1}^{a}\right)$ implies that $\operatorname{var}\left(\hat{y}_{1}\right)-\operatorname{var}\left(\hat{y}_{1}^{g}\right)$ must be the same for both countries; thus by equation (26), the trade deficits for both countries are the same in period one, implying that period-one trade must be balanced. Thus, we have shown that in the two standard cases, the assumptions of no risky assets and complete markets imply balanced trade.

When risky financial markets are incomplete, however, trade balances arise. Proposition 1 implies that

$$
p^{a}>p>p^{b}
$$

Thus, country $a$ goes short the risky asset and country $b$ goes long. By Proposition 3 , both countries run the same trade deficit, implying that neither country can run a trade deficit. But, as we explained above, since country a takes a long position, consumption variance and consequently consumption growth increases. Conversely, country $b$ takes a short position, which reduces consumption growth. Country $a$ thus runs a trade deficit in period one.

The fact that country a runs a trade deficit in one period and no trade surplus in the other suggests that country $a$ is getting the better deal from international trade. But equation (15) shows that this is not the case. The gains from trade are equal for both countries. Country $b$ gains from the reduction in the variance of consumption in period one. Country a gains from the increase in the level of consumption in period one.

Corollary 2 (General equilibrium) Consider a world with two countries $a$ and $b$. Suppose that $\pi_{0}^{a}=\pi_{0}^{b}$, and $A^{a}=A^{b}$. If markets are complete or if there are no risky assets, then 
trade is always balanced. If risky financial markets exist but are incomplete, then trade is balanced in period zero, gains from trade are equally shared, and:

$$
T D_{1}^{a} \gtreqless 0
$$

if and only if:

$$
\operatorname{var}\left(\hat{y}_{1}^{a}\right) \lesseqgtr \operatorname{var}\left(\hat{y}_{1}^{b}\right)
$$

and if $\operatorname{var}\left(\tilde{y}_{1}^{a}\right)=\operatorname{var}\left(\tilde{y}_{1}^{b}\right)$,

$$
R_{a}^{2} \lesseqgtr R_{b}^{2}
$$

Proof: Follows from Proposition 3. The assumption that $\pi_{0}^{a}=\pi_{0}^{b}$ and the fact that $\boldsymbol{\omega}^{a}=-\boldsymbol{\omega}^{b}$ guarantee that $T D_{0}^{a}=T D_{0}^{b}=0$ and that there are equal gains from trade. Since $\mathbf{P}^{\prime} \boldsymbol{\Sigma}^{-1} \mathbf{P}=\operatorname{var}\left(A \hat{y}_{1}\right)$ and $\mathbf{P}^{g^{\prime}} \boldsymbol{\Sigma}^{-1} \mathbf{P}^{g}=\operatorname{var}\left(A^{g} \hat{y}_{1}^{g}\right)$,

$$
T D_{1}^{g}=T D_{0}^{g}+\frac{1}{A^{g}}\left[\operatorname{var}\left(A \hat{y}_{1}\right)-\operatorname{var}\left(A^{g} \hat{y}_{1}^{g}\right)\right]
$$

If markets are complete, $\operatorname{var}\left(A^{g} \hat{y}_{1}^{g}\right)=\operatorname{var}\left(A \hat{y}_{1}\right)$ for both $g$, and trade is balanced in period one. If there are no risky assets, $\operatorname{var}\left(A^{g} \hat{y}_{1}^{g}\right)=0$ for both countries, and trade is also balanced in period one. If wlog, $\operatorname{var}\left(A^{g} \hat{y}_{1}^{a}\right)>\operatorname{var}\left(A^{g} \hat{y}_{1}^{b}\right)$, then $T D_{1}^{a}<T D_{1}^{b}$, and since $T D_{1}^{a}=-T D_{1}^{b}, T D_{1}^{a}<0$. If $\operatorname{var}\left(\tilde{y}_{1}^{a}\right)=\operatorname{var}\left(\tilde{y}_{1}^{b}\right)$,

$$
\operatorname{var}\left(\hat{y}_{1}^{a}\right) \lesseqgtr \operatorname{var}\left(\hat{y}_{1}^{b}\right) \Leftrightarrow R_{a}^{2} \lesseqgtr R_{b}^{2}
$$

\subsection{Markets that enable risk-sharing within countries}

We now focus on countries for which autarky excess returns equal global excess returns. By Proposition 3, such countries do not trade risky assets internationally. But households may still trade risky assets domestically. We show in this section that the extent of such trade affects the trade balance.

Formally, we assume that $\mathbf{P}^{g}=\mathbf{P}$. By Proposition 3,

$$
\begin{aligned}
& T D_{0}^{g}=\pi_{0} \frac{H^{g}}{\left(1+\pi_{0}\right) A^{g}} \ln \frac{\pi_{0}}{\pi_{0}^{g}}, \text { and } \\
& T D_{1}^{g}==T D_{0}^{g}-\frac{H^{g}}{A^{g}} \ln \frac{\pi_{0}}{\pi_{0}^{g}}=-\frac{1}{\pi_{0}} T D_{0}^{g} .
\end{aligned}
$$

So, if autarky prices of risky assets equal global prices, the sign and size of the trade balance in period zero depends on the autarky price of the riskless asset. Lower prices for the riskless asset lead to higher trade deficits. In Section 3, we identified 
four quantities that determine the autarky price of the riskless asset: national income growth; the subjective discount factor; absolute risk aversion; and the weighted sum of the variances. We now assume that the first three are the same, and, as promised, focus on the fourth. In other words, we now focus on:

$$
V^{g}=\frac{1}{H^{g}} \sum_{h \in g} \frac{A^{h}}{2} \operatorname{var}\left(\tilde{c}_{1, g}^{h}\right) .
$$

The autarky price of the riskless asset is increasing in, and the trade deficit is decreasing in, $V^{g}$. We analyze the effect of $V^{g}$ on the trade balance in three steps. We first decompose $V^{g}$ into two components. Next, we show how differences in the nature of financial markets lead to differences in $V^{g}$ and differences in trade deficits. As before, in these first two steps, we take global prices as given and analyze a small, open economy. Finally, we construct a general equilibrium model and show how incomplete markets lead to trade imbalances.

We now show how to decompose $V^{g}$ into an idiosyncratic and an aggregate risk component. For simplicity, we start by considering an economy with a single risky asset with unit variance. By equation (11),

$$
\operatorname{var}\left(\tilde{c}_{1}^{h}\right)=\operatorname{var}\left(\tilde{y}_{1}^{h}-\hat{y}_{1}^{h}\right)+\frac{1}{\left(A^{h}\right)^{2}}\left(p^{g}\right)^{2} .
$$

Multiplying by $A^{h}$ and summing across households yields:

$$
V^{g}=\underbrace{\frac{1}{H^{g}} \sum_{h \in g} A^{h} \operatorname{var}\left(\tilde{y}_{1}^{h}-\hat{y}_{1}^{h}\right)}_{\text {Non-marketed risk }}+\frac{1}{A^{g}}\left(p^{g}\right)^{2} .
$$

The first term on the right-hand side of equation (31) measures income risk that households cannot trade on markets - what we will call "non-marketed risk."

How do differences in financial markets lead to differences in $V^{g}$ ? By assumption, $p=p^{g}$ for all countries. So any differences in trade balances result from differences in non-marketed risk. Higher non-marketed risk leads to a higher price for the riskless asset and thus to lower trade deficits. Corollary 3 generalizes this argument to the multi-asset case and shows that the more assets that are traded in a country, the bigger a trade deficit that country will run.

Corollary 3 (Small open economy) Trade deficit in period zero is decreasing and trade deficit is period one is increasing in

$$
\sum_{h \in g} A^{h} \operatorname{var}\left(\tilde{y}_{1}^{h}-\hat{y}_{1}^{h}\right)
$$

All else being equal, if the assets traded in country a are a superset of the assets traded in country $b$, then country a runs a bigger trade deficit. 
Proof: Equation (11) implies that:

$$
\frac{1}{H^{g}} \sum_{h \in g} \frac{A^{h}}{2} \operatorname{var}\left(\tilde{c}_{1, g}^{h}\right)=\frac{1}{H^{g}} \sum_{h \in g} \frac{A^{h}}{2} \operatorname{var}\left(\tilde{y}_{1}^{h}-\hat{y}_{1}^{h}\right)+\left(1 / 2 A^{g}\right) \mathbf{P}^{g^{\prime}} \boldsymbol{\Sigma}^{-1} \mathbf{P}^{g}
$$

Holding $\mathbf{P}^{g}$ and all else constant, $\frac{1}{H^{g}} \sum_{h \in g} \frac{A^{h}}{2} \operatorname{var}\left(\tilde{c}_{1, g}^{h}\right)$ and therefore $\pi_{0}^{g}$ are increasing functions of $\sum_{h \in g} A^{h} \operatorname{var}\left(\tilde{y}_{1}^{h}-\hat{y}_{1}^{h}\right)$. Higher $\pi_{0}^{g}$ leads to a lower trade deficit in period 0 and a higher trade deficit in period 1. Elul (1997) first showed that more assets imply a lower price for the riskless asset in this model. Our proof follows Willen (forthcoming). Note that the optimal portfolio holdings defined in Proposition 1 are the solution to the problem:

$$
\begin{array}{r}
\min _{\left\{\omega_{0}^{h}, \boldsymbol{\omega}^{h}\right\}_{h \in g}} \frac{1}{H^{g}} \sum_{h \in g} \frac{A^{h}}{2} \operatorname{var}\left(\tilde{c}_{1, g}^{h}\right), \\
\text { st } \tilde{c}_{1}^{h}=\tilde{y}_{1}^{h}+\omega^{h}+\boldsymbol{\omega}^{h} \tilde{\mathbf{x}} .
\end{array}
$$

Adding an asset weakly relaxes the constraint, which reduces the price of the riskless asset and increases the trade deficit.

How do financial markets affect the quantity of non-marketed risk in an economy? All else being equal, countries with more-complete markets have less non-marketed risk. We use $R^{2}$, as defined in equation (27), to measure market incompleteness. We can re-write equation (31) as follows:

$$
V^{g}=\frac{1}{H^{g}} \sum_{h \in g} A^{h}\left(1-R_{h}^{2}\right) \operatorname{var}\left(\tilde{y}_{1}^{h}\right)+\frac{1}{A^{g}}\left(p^{g}\right)^{2} .
$$

Equation (32) identifies differences in trade balances across countries. First, all else being equal, a country in which household $R_{h}^{2}$ 's are uniformly higher will run a higher trade deficit. Second, suppose that each household has the same variance of income and the same risk aversion. Then, higher average $R_{h}^{2}$ leads to higher trade deficits. Finally, suppose that both countries are identical, but in one country, available risky assets are a superset of the assets available in another country. In a regression, the presence of more regressors necessarily implies a higher $R^{2}$. Similarly, more assets imply higher $R_{h}^{2}$ 's. Thus, more assets, all else being equal, imply higher trade deficits.

We now show that if a world is populated by just two countries, then differences in market completeness across countries yield trade imbalances. Consider two countries, $a$ and $b$. Assume that $p=p^{a}=p^{b}=0$, that income growth equals zero, that $\delta^{a}=\delta^{b}=1, A^{h}=A$ for all $h$, that there are the same number of households in both countries, that corresponding households have the same variance of income, and that 
the variance of aggregate income is the same in both countries. Equation (8) implies that

$$
\begin{aligned}
\pi_{0}^{a} & =\exp \frac{1}{H} \sum_{h \in a} \frac{A}{2} \operatorname{var}\left(\tilde{y}_{1}^{h}-\hat{y}_{1}^{h}\right) \text { and } \\
\pi_{0}^{b} & =\exp \frac{1}{H} \sum_{h \in b} \frac{A}{2} \operatorname{var}\left(\tilde{y}_{1}^{h}-\hat{y}_{1}^{h}\right) .
\end{aligned}
$$

If markets are complete within countries, then $\operatorname{var}\left(c_{1}^{h}\right)=0$ for all households and $\pi_{0}^{a}=\pi_{0}^{b}$ and $\pi_{0}=\pi_{0}^{a}=\pi_{0}^{b}$ is an equilibrium in which trade is balanced. If there are no risky financial markets in either country, $\operatorname{var}\left(c_{1}^{h}\right)=\operatorname{var}\left(y_{1}^{h}\right)$ for all households and $\pi_{0}^{a}=\pi_{0}^{b}$ and $\pi_{0}=\pi_{0}^{a}=\pi_{0}^{b}$ is again an equilibrium in which trade is balanced. Only if there are differences in market incompleteness will trade deficits emerge in this economy.

Corollary 4 extends the above argument that countries with more-complete markets run trade deficits with countries with less-complete markets to the more general case where there are many risky assets and autarky excess returns do not necessarily equal zero.

Corollary 4 (General equilibrium) Consider a world with two countries, $a$ and $b$. Suppose that $\mathbf{P}^{a}=\mathbf{P}^{b}, A^{a}=A^{b}, \delta^{a}=\delta^{b}$, and $\mathrm{E}\left(\tilde{y}_{1}^{a}\right)-y_{0}^{a}=\mathrm{E}\left(\tilde{y}_{1}^{b}\right)-y_{0}^{b}$. If markets are complete, then trade is always balanced.

1. Suppose $A^{h}=A$ and $\operatorname{var}\left(y_{1}^{h}\right)=V$ for all $h$. If there are no risky financial markets, then trade is balanced. If markets are incomplete

$$
T D_{0}^{a} \gtreqless 0 \Leftrightarrow T D_{0}^{a} \lesseqgtr 0 \Leftrightarrow \frac{1}{H} \sum_{h \in a} R_{h}^{2} \gtreqless \frac{1}{H} \sum_{h \in b} R_{h}^{2} .
$$

2. Consider a world with two countries, $a$ and $b$, identical in every respect except that the household portfolio choice menu in country $a$ is a superset of the portfolio choice menu in country $b$. Then, country a runs a trade deficit with country $b$ in period 0 and a surplus in period 1.

Proof: If markets are complete, equation (12) implies that $\operatorname{var}\left(\tilde{y}_{1}^{h}-\hat{y}_{1}^{h}\right)=0$ for all $h$, so

$$
\frac{1}{H^{g}} \sum_{h \in g} \frac{A^{h}}{2} \operatorname{var}\left(\tilde{c}_{1, g}^{h}\right)=\left(1 / 2 A^{g}\right) \mathbf{P}^{g^{\prime}} \boldsymbol{\Sigma}^{-1} \mathbf{P}^{g} .
$$

Thus, under the maintained assumption, autarky prices of the risky asset must be the same in both countries, and trade is balanced. If $A^{h}=A$ and $\operatorname{var}\left(y_{1}^{h}\right)=V$, 
$\operatorname{var}\left(\tilde{y}_{1}^{h}-\hat{y}_{1}^{h}\right)=\left(1-R_{h}^{2}\right) V$, and

$$
\frac{1}{H^{g}} \sum_{h \in g} \frac{A^{h}}{2} \operatorname{var}\left(\tilde{c}_{1, g}^{h}\right)=A \cdot V \cdot\left(1-\frac{1}{H^{g}} \sum_{h \in b} R_{h}^{2}\right)+\left(1 / 2 A^{g}\right) \mathbf{P}^{g^{\prime}} \boldsymbol{\Sigma}^{-1} \mathbf{P}^{g} .
$$

Higher average $R^{2}$ implies a lower autarky price and thus a higher trade deficit. Since both countries can't run a trade deficit, the country with the higher trade deficit runs a trade deficit and the county with the lower trade deficit runs a surplus. Part 2 follows directly from Corollary 3 .

\section{Conclusions}

We have shown that incomplete markets can generate trade imbalances. In the conclusion, we briefly discuss some limitations of our approach, and the potential empirical relevance of the paper.

Our analytical approach, a two-period, exponential-normal model, has obvious limitations. As a two-period model, the model misses many interesting interactions between market incompleteness and dynamics. In particular, in a multi-period model, households can self-insure, reducing the need for risky asset markets. However, this limitation is not very costly. Households cannot self-insure against permanent shocks, and empirical evidence suggests that permanent shocks are significant at both the household and the aggregate level. For a treatment of this model in a dynamic context, see Davis, Nalewaik, and Willen (2001). Thus, the two-period nature of the model is not a major drawback, but exponential utility and normal returns potentially are. For example, exponential utility and normal returns guarantee that an additional asset lowers the autarky price of the riskless asset. While this is typically true in incomplete market models, Elul (1997) shows that it is generically possible to find a new asset that arbitrarily perturbs the riskless rate in an arbitrary model without exponential utility and normal returns. Thus, we can extrapolate from Elul's work that, although the results in this paper typically hold in more general setups, we can certainly find situations in which they don't.

Is the phenomenon of incomplete-market-induced trade imbalances empirically relevant? The results of Section 4.2 show that countries with more-complete markets run trade deficits with countries with less-complete markets. One might argue that the United States, with the most sophisticated capital markets in the world, has more complete markets than any other country. Thus, the fact that the United States also runs large trade deficits is consistent with the theory. On the other hand, the results of Section 4.1 predict that the more national income is spanned by risky 
assets, the smaller a country's trade deficits with the rest of the world. Research on the covariance of national income with various financial assets has only scratched the surface (See Bottazzi, Pesenti and van Wincoop (1996) and Davis, Nalewaik and Willen (2001)), and thus the issue remains an open question.

\section{References}

Adler, M. and Dumas, B. (1983). International portflio choice and corporation finance: A synthesis, Journal of Finance 38(3): 925-984.

Baxter, M. and Crucini, M. J. (1995). Business cycles and the asset structure of foreign trade, International Economic Review 36(4): 821-54.

Bottazzi, L., Pesenti, P. and van Wincoop, E. (1996). Wages, profits and the international portfolio puzzle, European Economic Review 40(2): 219-254.

Boyd, J. H. and Smith, B. D. (1992). Intermediation and the equilibrium allocation of investment capital: Implications for economic development, Journal of Monetary Economics 30.

Davis, S., Nalewaik, J. and Willen, P. (2001). On the gains to international trade in risky financial assets. Working paper. University of Chicago.

Demange, G. and Laroque, G. (1995). Optimality of incomplete markets, Journal of Economic Theory 65(1): 218-232.

Dixit, A. and Norman, V. (1980). Theory of International Trade, Cambridge University Press, Cambridge.

Elul, R. (1997). Financial innovation, precautionary saving and the risk-free rate, Journal of Mathematical Economics 27(1): 113-131.

Errunza, V. and Losq, E. (1985). International asset pricing under mild segmentation: Theory and test, Journal of Finance (1): 105-124.

Errunza, V. and Losq, E. (1989). Capital flow controls, international asset pricing and investors' welfare: A multi country framework, Journal of Finance 44(4): 10251037.

Geanakoplos, J. (1990). An introduction to general equilibrium with incomplete asset markets, Journal of Mathematical Economics 19(1-2): 1-38. 
Gertler, M. and Rogoff, K. (1990). North-south lending and endogenous domestic capital market inefficiencies, Journal of Monetary Economics 26(2).

Levine, R. (2004). Finance and growth: Theory and evidence, NBER Working Paper 10766.

Obstfeld, M. and Rogoff, K. (1996). Foundations of International Macroeconomics, MIT Press, Cambridge.

Svensson, L. E. O. (1988). Trade in risky assets, American Economic Review 78(3): 375-394.

Willen, P. (forthcoming). New financial markets: Who gains and who loses, Economic Theory . 